\title{
Assessing the Visual Quality of Urban Landscapes Influenced by the Presence of Fruit Trees
}

\author{
Tabita-Teodora LISANDRU ${ }^{1 *}$, Viorel MITRE ${ }^{1}$, Adelina DUMITRAS ${ }^{1}$, Monica PAL ${ }^{1}$, Andreea TRIPON ${ }^{1}$ \\ ${ }^{1}$ Department of Horticulture and Landscape Architecture. University of Agricultural Sciences and \\ Veterinary Medicine, Calea Mănăștur 3-5, Cluj-Napoca 400372, Romania \\ *)Corresponding author, e-mail: tabita.lisandru@usamvcluj.ro
}

BulletinUASVM Horticulture 73(2) / 2016

Print ISSN 1843-5254, Electronic ISSN 1843-5394

DOI:10.15835/buasvmcn-hort:11956

\begin{abstract}
The study was carried out to evaluate the visual quality of urban landscapes influenced by the use of fruit trees by applying the Scenic Beauty Estimation Method (SBE). Thirty students from the University of Agricultural Sciences and Veterinary Medicine Cluj-Napoca (Romania), Faculty of Horticulture, were asked to assign scenic beauty values to different landscapes with and without fruit trees in Cluj-Napoca urban areas. The results show that fruit trees have a positive impact on the aesthetic value of perceived urban landscape scenery.
\end{abstract}

Keywords: design, fruit trees, urban ecosystems, visual perception

\section{INTRODUCTION}

Urbanization, highway development, surface mining, the siting of dams, the layout of utility corridors, the building of power plants - all of these activities go on without much regard for the landscape's potential as a visual resource. Scenic landscapes should be regarded as an important natural resource, just as vital as timber, water, soil, mineral ores and fossil fuels (Kane, 1981). Trees are essential elements of scenic landscapes and their perceived value is determinant for successful public spaces design (Raskovic and Decker, 2015). They are valuable components of urban areas, playing an important role in visual perception of urban ecosystems. Without trees the ecology of the Earth would be unbalanced, the amount of oxygen would decrease and the natural food and plant chain would be broken. Trees highly contribute to the improvement of the landscape quality through their aesthetic, ecological, social and economic benefits. Trees also provide beauty, shade, protection and comfort for man and animals. In the last years, beside trees, fruit trees presence can be noticed not only in private gardens but also in urban areas being part of the public greenery design. Planted by landscape designers or by community, fruit trees contribute to the visual quality of the urban areas through their untapped beauty (form, texture, variety of color). According to Fischer (2007), fruit trees are part of the urban ecosystems, offering multiple uses from nature conservation to fruit production. The aim of this paper was to analyze the scenic beauty perception ensured by existing fruit trees in urban landscapes.

\section{MATERIALS AND METHODS}

In order to determine the visual effects of existing fruit trees in urban ecosystems the Scenic Beauty Estimation Method was applied. SBE is the most commonly used method as a measure of landscape beauty derived from observer's judgments in visual assessment research (Daniel and Boster, 1976). Beauty in landscape comes 
from two main sources which cannot be separated: from the object and from the observer (Laurie, 1975). The central achievement of the SBE is its ability to assign scenic beauty values along an interval scale where their relative numeric values reflect measured differences in perceived beauty, but not in reference to a true zero value (Ingardeen, 1973; Ulrich, 1983). Ten photos of fruit trees were randomly taken from different parts of Cluj-Napoca city and analyzed based on a questionnaire. The survey had two parts: the first part concerns the visual quality of the landscape with fruit trees, while the second part concerns the visual perception of the same urban landscapes in the absence of fruit trees. Photoshop CS6 program was used to eliminate fruit trees from the landscape photos in order to analyze the visual quality of the urban landscapes with the existence and without existence of fruit trees. Thirty students $(\mathrm{N}=30)$ from the Landscape Architecture Department of the Horticulture Faculty, University of Agricultural Sciences and Veterinary Medicine Cluj-Napoca have been surveyed. They were asked to evaluate the given landscapes on a scale from a "low beauty" to "high beauty", assigning values from 1 to 7 from a numeric interval scale, taking into consideration the following aspects: harmony, degree of naturalness, fascination, color intensity and diversity. The statistical analyses have been determined by using the SPSS 13.0 statistics program. The results were obtained using Pearson correlations.

\section{RESULTS AND DISCUSSION}

The results regarding the scenic beauty of the analyzed urban landscapes with fruit trees are presented in Table 1 . The most significant

Tab. 1. Visual quality of urban landscapes provided by the presence of fruit trees

\begin{tabular}{cccc}
\hline $\begin{array}{c}\text { Visual quality of urban areas granted by the } \\
\text { existing fruit trees }\end{array}$ & N & $\begin{array}{c}\text { Average visual quality index (AVQ } \\
\text { index) }\end{array}$ & Std. Deviation \\
\hline With fruit trees (FT01) & 30 & 4.0733 & 1.54614 \\
\hline With fruit trees (FT02) & 30 & 5.1800 & 1.35146 \\
\hline With fruit trees (FT03) & 30 & 5.1000 & 1.40350 \\
\hline With fruit trees (FT04) & 30 & 4.6333 & 1.43969 \\
\hline With fruit trees (FT05) & 30 & 4.7067 & 1.42625 \\
\hline With fruit trees (FT06) & 30 & 3.7400 & 1.43508 \\
\hline With fruit trees (FT07) & 30 & 4.5000 & 1.41777 \\
\hline With fruit trees (FT08) & 30 & 4.3133 & 1.32673 \\
\hline With fruit trees (FT09) & 30 & 4.8933 & 1.25397 \\
\hline With fruit trees (FT010) & 30 & 3.9800 & 1.36333 \\
\hline
\end{tabular}

Tab. 2. Visual quality of urban landscapes without fruit trees

\begin{tabular}{cccc}
\hline $\begin{array}{c}\text { Visual quality of urban areas provided by the } \\
\text { absence of fruit trees }\end{array}$ & $\mathrm{N}$ & $\begin{array}{c}\text { Average visual quality index (AVQ } \\
\text { index) }\end{array}$ & Std. Deviation \\
\hline Without fruit trees (WFT01) & 30 & 3.5600 & 1.71249 \\
\hline Without fruit trees (WFT02) & 30 & 3.9400 & 1.63531 \\
\hline Without fruit trees (WFT03) & 30 & 3.8000 & 1.37572 \\
\hline Without fruit trees (WFT04) & 30 & 3.9533 & 1.52974 \\
\hline Without fruit trees (WFT05) & 30 & 2.9067 & 1.26038 \\
\hline Without fruit trees (WFT06) & 30 & 3.3400 & 1.45090 \\
\hline Without fruit trees (WFT07) & 30 & 3.9400 & 1.44348 \\
\hline Without fruit trees (WFT08) & 30 & 3.7400 & 1.43040 \\
\hline Without fruit trees (WFT09) & 30 & 3.9067 & 1.42531 \\
\hline Without fruit trees (WFT010) & 30 & 3.3267 & 1.36346 \\
\hline
\end{tabular}


difference was shown in the case of photo FT02 (with fruit trees 02) representing an average VQ index $=5.1800$, followed by the photo FT03 with a VQ index=5.1000 and the photo FT09, VQ index $=4.8933$ (Fig.1).

Table 2 shows the results regarding the visual perception of the same urban landscapes in the
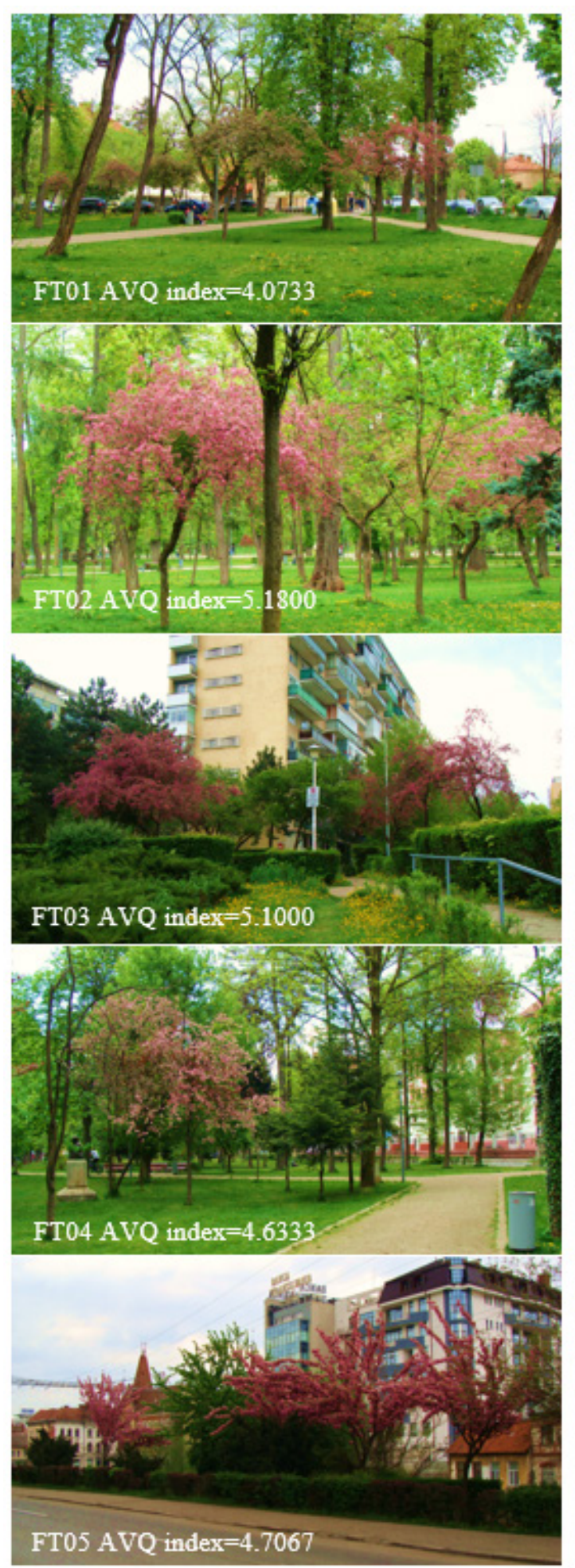

absence of fruit trees. The highest appreciation was shown in the case of photo WFT04 (without fruit trees 04) with an average VQ index=3.9533, followed by the photo WFT07 representing an average VQ index $=3.9400$ and the photo WFT09 with an average VQ index=3.9067 (Fig.2).
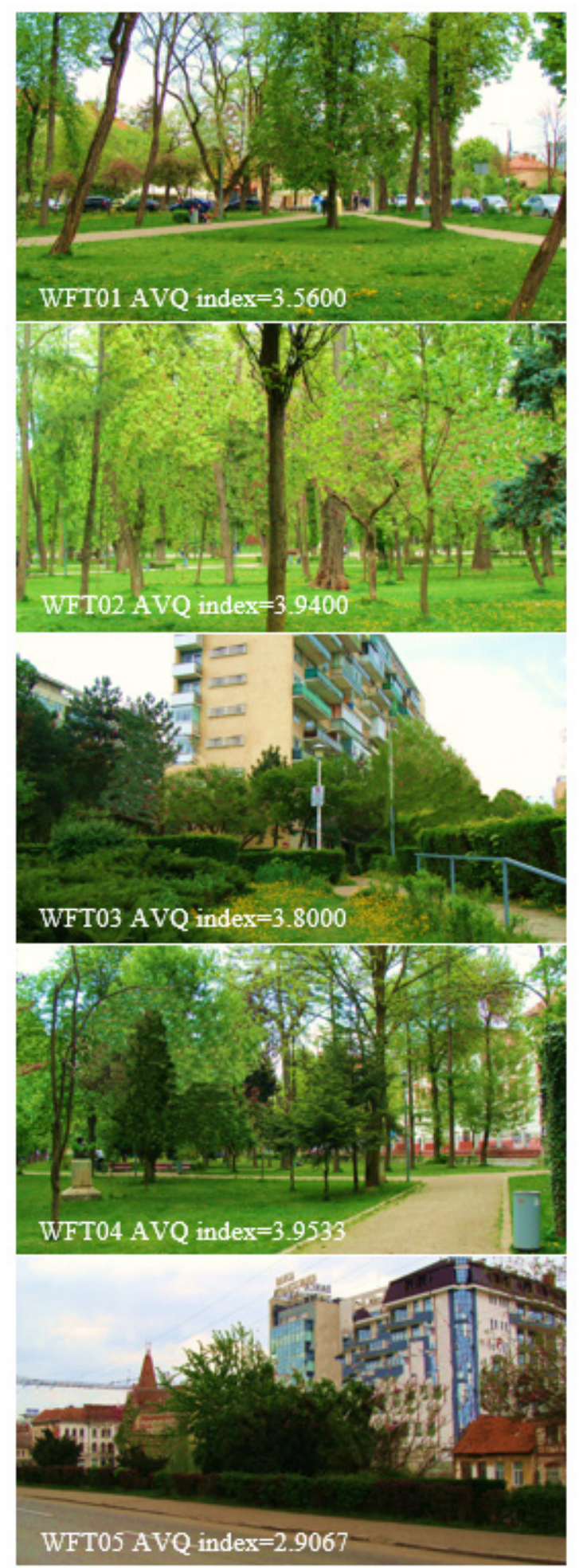

Bulletin UASVM Horticulture 73(2) / 2016 


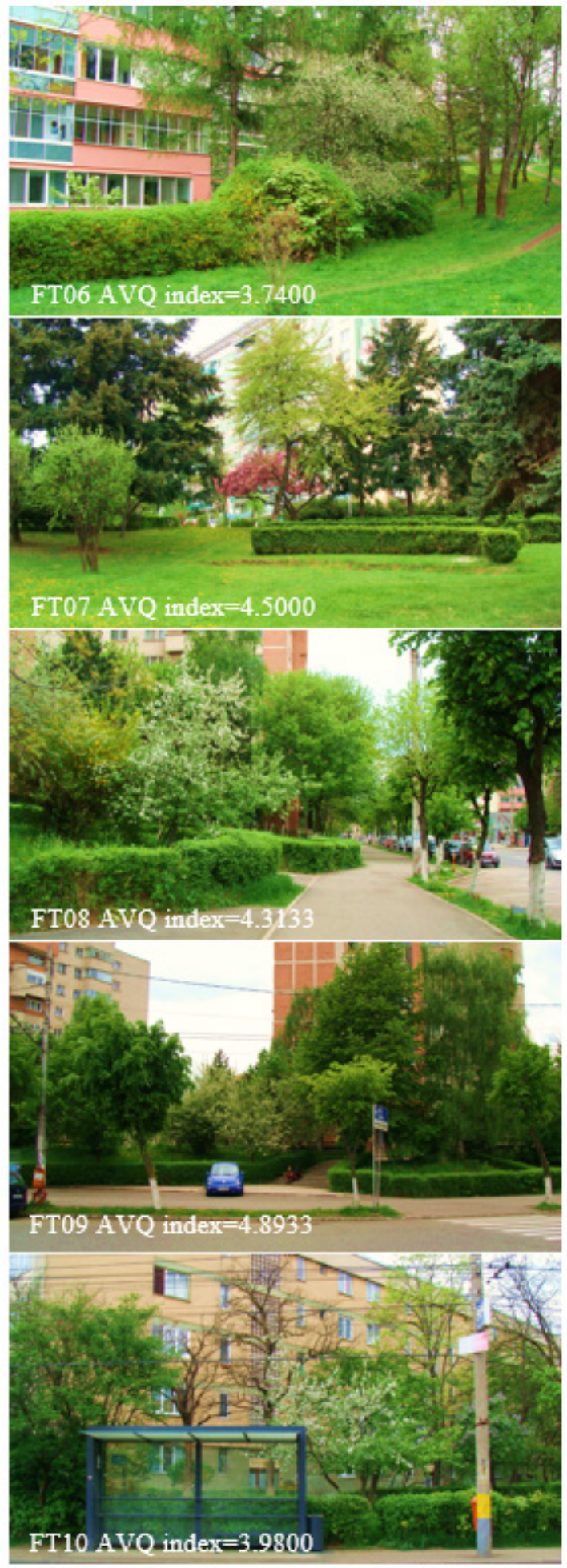

Fig. 1. Urban landscapes with fruit trees

Data presented in Table 3 were obtained by applying correlation analysis of the interval scale concerning the relationship between the visual quality index of the analyzed urban landscapes with and without fruit trees. Results show that

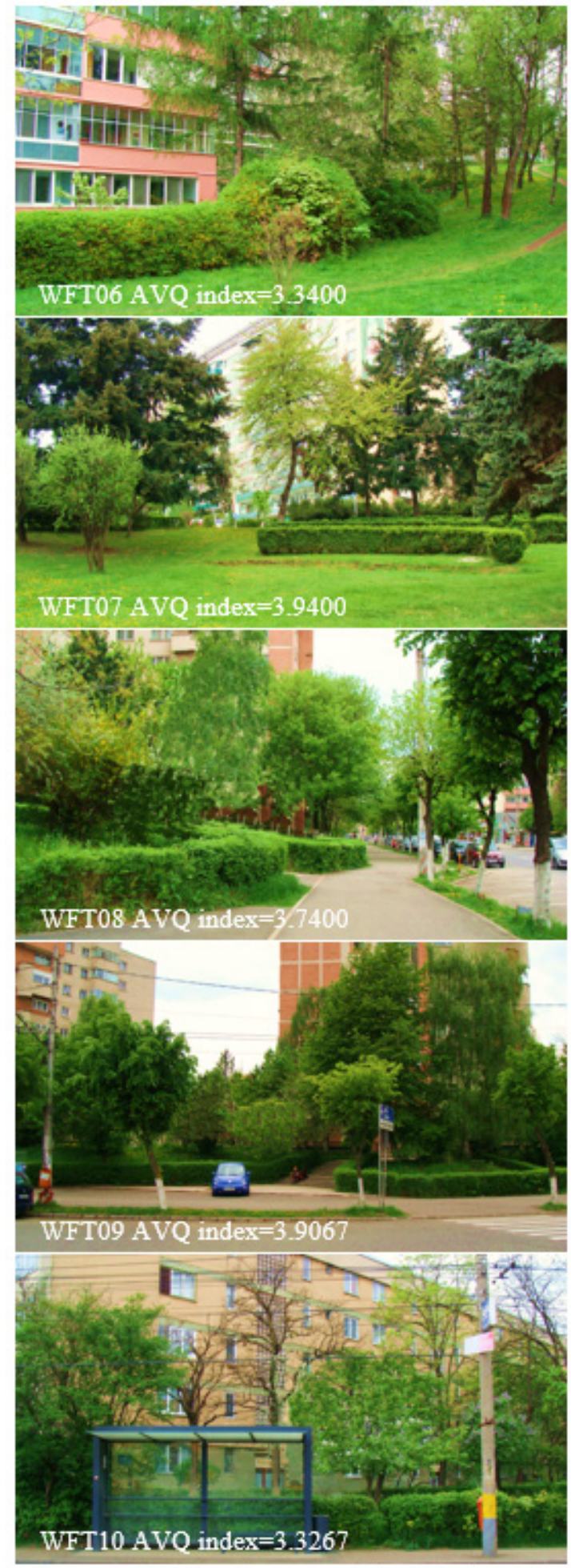

Fig. 2. Urban landscapes without fruit trees

there is a significant difference between fruit tree landscapes and scenes without fruit trees, except the scene 2 (FT02-WFT02) where the presence or the absence of fruit trees in urban landscapes show no influence/change on the scene perceived 
Tab. 3. Correlation analysis of scenic beauty of urban landscapes with and without fruit trees

\begin{tabular}{|c|c|c|c|c|c|c|c|c|c|c|}
\hline & FT01 & FT02 & FT03 & FT04 & FT05 & FT06 & FT07 & FT08 & FT09 & FT010 \\
\hline WFT01 & $.206^{*}$ & & & & & & & & & \\
\hline WFT02 & & 0.13 & & & & & & & & \\
\hline WFT03 & & & $.474^{* *}$ & & & & & & & \\
\hline WFT04 & & & & $.320^{* *}$ & & & & & & \\
\hline WFT05 & & & & & $.187^{*}$ & & & & & \\
\hline WFT06 & & & & & & $.557^{* *}$ & & & & \\
\hline WFT07 & & & & & & & $.560^{* *}$ & & & \\
\hline WFT08 & & & & & & & & $.472^{* *}$ & & \\
\hline WFT09 & & & & & & & & & $.430 * *$ & \\
\hline WFT010 & & & & & & & & & & $.555^{* *}$ \\
\hline
\end{tabular}

by the observers. Also, in similar studies (Bulut et al., 2010) the results obtained show that the presence of fruit trees considerably increase the visual quality of the urban landscape. According to Bulut et al. (2010), fruit trees with their flowers in spring, with their fruits in summer, with the color of their leaves in autumn and with their calligraphic characteristics and fruits in winter have positive influences on the aesthetic value of perceived landscape scenery.

\section{CONCLUSIONS}

In our over-populated century there has never been more important to reintroduce fruit trees in urban landscapes to create environmentally sustainable areas. The results of the study show that scenic beauty of the landscape is highly increased by the presence of fruit trees in urban areas. According to the results fruit trees play an important role in determining the visual quality of the landscapes due to their versatile characters.

\section{REFERENCES}

1. Bulut Z, Sezen I, Karahan F (2010). Determination of spring visual ceremonies of urban fruit trees and shrubs: A case study from Erzurum, Turkey. Journal of Food, Agriculture \& Environment (1): 289 - 296.

2. Daniel T, Boster R (1976). Measuring Landscape Esthetisc: The Scenic Beauty Estimation Method. USDA Forest Service, Research Paper RM-167.

3. Fischer M (2007). Streuobst-Betreiberkonzepte und Sortenempfehlung, Erwerbs-Obstbau, 49.4: 141-147

4. Ira Bruce N (1977). Trees in the City. 1-2

5. Ingardeen R (1973). Aesthetic Experience and Aesthetic Object. In M. Lipman, Contemporary Aesthetics. Boston: Allyn and Bacon.

6. Kane SK (1981). Assessing landscape attractiveness: a comparative test of two new methods. Applied Geography 1. 77-96

7. Laurie IC (1975). Aesthetic factors in visual evaluation. In: Zube, E.N., Brush, R.O., Fabos, J.G. (Eds.), Landscape Assessment: Values, Perceptions and Resources. Dowden Hutchinson and Ross, Stroudsburg, pp. 102-117.

8. Raskovic S, Decker R (2015). The influence of trees on the perception of urban squares. Urban Forestry \& Urban Greening 14 237-245.

9. Ulrich RS (1983). Aesthetic and Affective Response to Natural Environment. In. 1. Altman and J. F. Wohlwill (Eds.) Human Behavior and Environment. 